\title{
Penerapan Logika Fuzzy \\ Pada Penilaian Mutu Dosen Terhadap Tri Dharma Perguruan Tinggi
}

\author{
Mochamad Adhari Adiguna ${ }^{1}$, Adi Muhajirin' \\ ${ }^{1,2}$ Universitas Pamulang, Universitas Bhayangkara Jakarta Raya \\ moch.adhari@gmail.com
}

\begin{abstract}
Abstrak-Tri Dharma Perguruan Tinggi merupakan kegiatan yang harus dilakukan oleh setiap Dosen, karena hal tersebut termasuk beban kerja Dosen sesuai peraturan Presiden No 4 Tahun 2014 RI. Dalam pelaksanaannya, Perguruan Tinggi memiliki peran penting agar dapat mendukung dan mengevaluasi kegiatan tersebut. Salah satu evaluasi yang dapat digunakan yaitu penilaian mutu Dosen terhadap beban kerja Dosen tersebut. Pada penelitian ini dirancang aplikasi untuk menerapkan logika Fuzzy untuk perhitungan nilai mutu Dosen terhadap pelaksanaan Tri Dharma Perguruan Tinggi. Latar belakang dari penelitian ini ingin mengetahui hasil yang didapat dari penerapan dan perhitungan menggunakan logika Fuzzy, juga membantu evaluasi Dosen pada bidang pengendali mutu. Pada penerapannya digunakan 27 aturan/rules untuk komposisi aturannya, himpunan Fuzzy dengan semesta dan aplikasi fungsi implikasi pada satu kondisi nilai yang selanjutnya dihitung menggunakan penalaran/inferensi dan defuzzifikasi. Batasan masalah dari penelitian ini menerapkan logika Fuzzy pada variabel pendidikan, penelitian dan pengabdian sehingga menghasilkan output yang sesuai. Adapun logika Fuzzy yang digunakan yaitu Fuzzy mamdani. Hasil pengujian pada aplikasi menunjukan $100 \%$ bekerja dengan baik, selisih nilai antara pengujian dan penalaran, hasil pengujian 2,36 lebih kecil dari hasil penalaran.
\end{abstract}

Kata kunci-Logika Fuzzy, Penilaian Mutu Dosen, Tri Dharma Perguruan Tinggi.

\section{PENDAHULUAN}

Dosen merupakan pekerja profesi yang harus melakukan tri dharma perguruan tinggi yang termasuk pada beban kerja dosen. Sesuai PP No 4 Tahun 2014 RI. Perguruan Tinggi memiliki otonomi untuk mengelola sendiri lembaganya sebagai pusat penyelenggaraan Tri Dharma Perguruan Tinggi. Otonomi di bidang akademik, yang meliputi penetapan norma dan kebijakan operasional serta pelaksanaan pendidikan dan serta pengabdian kepada masyarakat, sesuai dengan ketentuan peraturan perundang-undangan. Untuk itu diperlukan satu aplikasi untuk menghitung penilaian mutu Dosen terhadap Tri Dharma Perguruan Tinggi tersebut. pada penelitian ini, kami bermaksud melakukan penerapan logika Fuzzy pada aplikasi penilaian mutu Dosen terhadap pelaksanaan tri dharma perguruan tinggi.

Kriteria penilaian mutu Dosen dilakukan menggunakan input 3 variabel yaitu variabel pendidikan, penelitian dan pengabdian kepada masyarakat.

Latar belakang dari penelitian ini ingin mengetahui hasil yang didapat dari perhitungan menggunakan logika Fuzzy pada penilaian mutu Dosen.

Pada penelitian Andreas Widiyantoro dkk., Konsep tentang logika Fuzzy diperkenalkan oleh Prof. Lotfi Astor Zadeh pada 1962. Logika Fuzzy adalah metodologi sistem kontrol pemecahan masalah yang cocok untuk diimplementasikan pada sistem, mulai dari sistem yang sederhana, sistem kecil, embedded system, jaringan PC, multi-channel atau workstation berbasis akuisisi data, dan sistem kontrol. Metodologi ini dapat diterapkan pada perangkat keras, perangkat lunak, atau kombinasi keduanya [1] [2] [4].

Batasan masalah dari penelitian ini menerapkan logika Fuzzy pada variabel pendidikan, penelitian dan pengabdian masyarakat sehingga menghasilkan output yang sesuai. Adapun logika Fuzzy yang digunakan yaitu Fuzzy mamdani.

Metode mamdani sering dikenal dengan metode Maxmin. Metode ini diperkenalkan oleh Ebrahim Mamdani pada tahun 1975. Untuk mendapatkan output, diperlukan tahapan-tahapan pembentukan himpunan Fuzzy, aplikasi fungsi implikasi dan kompisisi aturan [3].

Penerapan logika Fuzzy pada aplikasi untuk penilaian mutu Dosen terhadap tri dharma perguruan tinggi ini menggunakan pemrograman GUI (Graphic User Interface) Matlab R2009a.

\section{PEMBAHASAN}

\section{A. BAHAN DAN METODE}

Dalam penyusunan penerapan logika Fuzzy mamdani untuk penilaian mutu Dosen terhadap Tri Dharma Perguruan Tinggi ini dilakukan beberapa langkah untuk mendapatkan data yang valid dalam penyusunannya. Hal tersebut dilakukan untuk mendapatkan hasil yang sesuai. 


\section{Menentukan Himpunan Fuzzy}

Variabel Pendidikan

Variabel pendidikan digunakan untuk mengukur nilai pendidikan/pengajaran Dosen mengampu mata kuliah. Berikut himpunan Fuzzy pada variabel pendidikan:

Tabel 1. Himpunan Fuzzy variabel pendidikan

\begin{tabular}{|l|l|l|}
\hline No & $\begin{array}{l}\text { Sks } \\
\text { diampu }\end{array}$ & $\begin{array}{l}\text { Tingkat } \\
\text { Fuzzy }\end{array}$ \\
\hline 1 & $0-8$ & Kurang \\
\hline 2 & $6-12$ & Cukup \\
\hline 3 & $10-16$ & Baik \\
\hline
\end{tabular}

Variabel Penelitian

Variabel penelitian digunakan untuk mengukur nilai Dosen dalam membuat dan mempublikasi karya ilmiahnya, baik nasional maupun internasional. Berikut himpunan Fuzzy pada variabel penelitian:

Tabel 2. Himpunan Fuzzy variabel penelitian

\begin{tabular}{|l|l|l|}
\hline No & $\begin{array}{l}\text { Karya } \\
\text { Ilmiah }\end{array}$ & $\begin{array}{l}\text { Tingkat } \\
\text { Fuzzy }\end{array}$ \\
\hline 1 & $0-1$ & Kurang \\
\hline 2 & $1-2$ & Cukup \\
\hline 3 & $2-3$ & Baik \\
\hline
\end{tabular}

Variabel Pengabdian

Variabel pengabdian digunakan untuk mengukur nilai pengabdian Dosen kepada masyarakat. Berikut himpunan Fuzzy pada variabel pengabdian:

Tabel 3. Himpunan Fuzzy variabel pengabdian

\begin{tabular}{|l|l|l|}
\hline No & $\begin{array}{l}\text { Jumlah } \\
(\mathbf{x})\end{array}$ & $\begin{array}{l}\text { Tingkat } \\
\text { Fuzzy }\end{array}$ \\
\hline 1 & $0-1$ & Kurang \\
\hline 2 & $1-2$ & Cukup \\
\hline 3 & $2-3$ & Baik \\
\hline
\end{tabular}

Variabel Hasil

Variabel hasil merupakan output dari hasil perhitungan dan penerapan logika Fuzzy pada penilaiannya. Berikut himpunan Fuzzy pada variabel hasil:

Tabel 4. Himpunan Fuzzy variabel hasil

\begin{tabular}{|l|l|l|}
\hline No & $\begin{array}{l}\text { Jumlah } \\
(\mathbf{x})\end{array}$ & $\begin{array}{l}\text { Tingkat } \\
\text { Fuzzy }\end{array}$ \\
\hline 1 & $0-4$ & Kurang \\
\hline 2 & $3,6-6$ & Cukup \\
\hline 3 & $6-7,3$ & Baik \\
\hline
\end{tabular}

Himpunan Fuzzy untuk input dan output, tergambar pada membership function berikut:

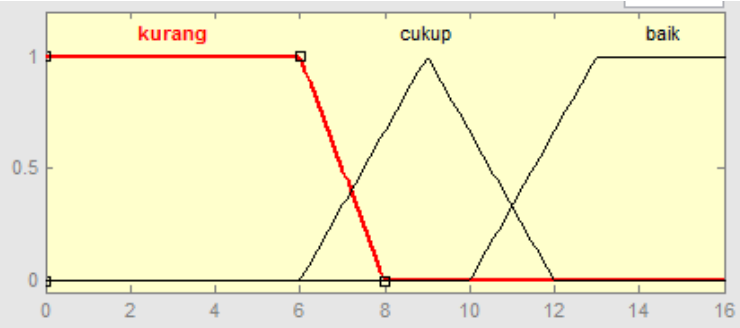

Gambar 1. Membership function variabel pendidikan

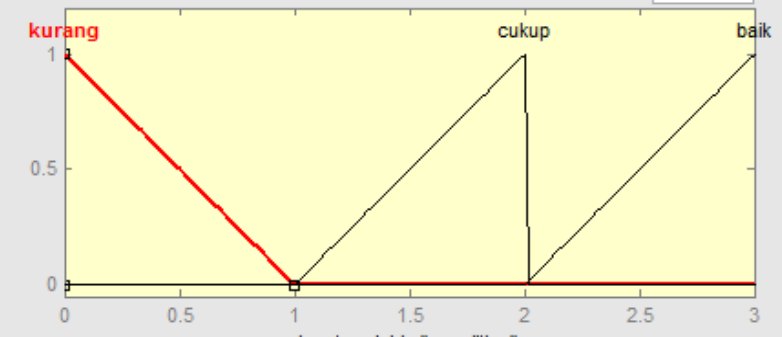

Gambar 2. Membership function variabel penelitian dan pengabdian

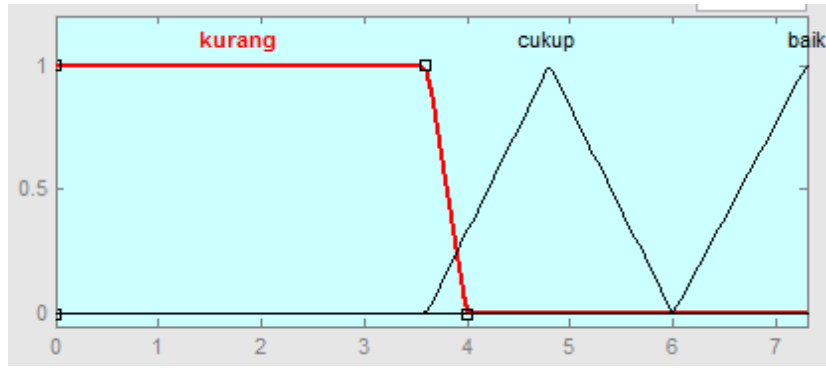

Gambar 3. Membership function variabel hasil

Dalam penerapannya terdapat 3 variabel input dan 1 variabel output. Seperti pada gambar 4 berikut ini:

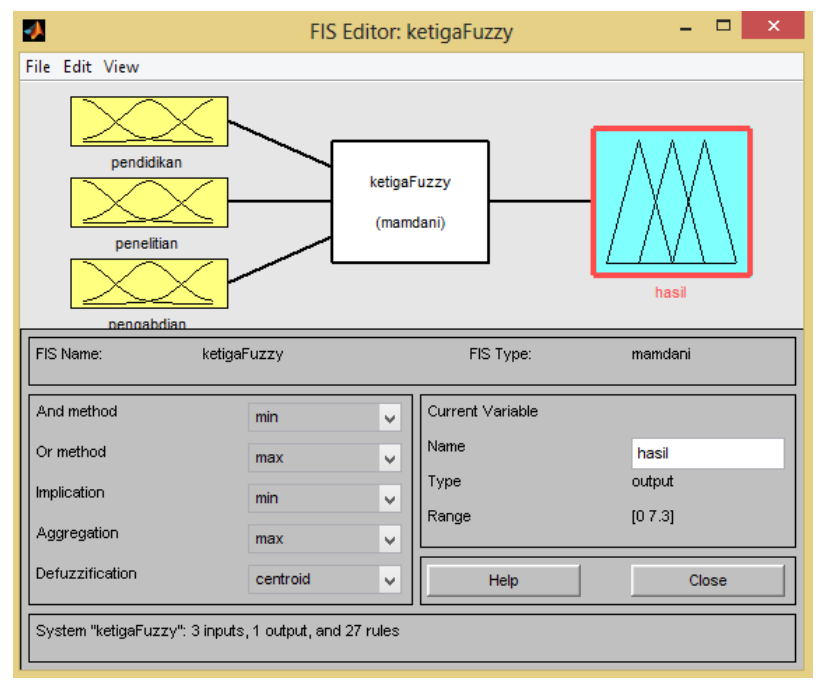

Gambar 4. Fis Editor 
$\underline{\text { Analisa Proses }}$

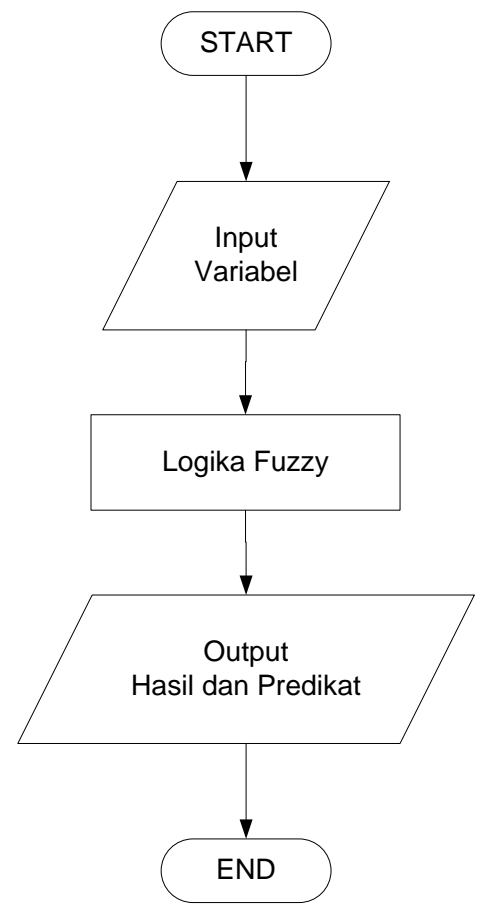

Gambar 5. Analisa Proses

Analisa Data

Data diambil satu kasus dengan nilai pendidikan $=12$, penelitian $=2$, pengabdian $=1$.

Pemrosesan Data

Data yang diinput berupa nilai variabel pendidikan, penelitian dan pengajaran yang selanjutnya diproses oleh logika Fuzzy dan menghasilkan keluaran nilai dan predikat. Keluaran predikat disesuaikan dengan komposisi aturan yang telah dibentuk.

\section{HASIL DAN UJICOBA}

Setelah dilakukan perhitungan dan percobaan, maka didapatlah hasil menggunakan metode Fuzzy mamdani dengan Matlab.

Aplikasi Fungsi Implikasi

Setelah aturan dibentuk, selanjutnya dilakukan aplikasi fungsi implikasi.

pendidikan $=12$

$$
\text { uKurang [12] }\left\{\begin{array}{c}
1: X_{1} \leq 6 \\
=\frac{5-x_{1}}{2}: 6 \leq X_{1} \leq 8 \\
0: X_{1} \geq 8
\end{array}\right.
$$

$$
\begin{aligned}
& \text { uCukup [12] }\left\{\begin{array}{c}
0: X_{1} \leq 6 \circ \operatorname{ctcu} X_{1} \geq 12 \\
=\frac{X_{1}-6}{2}: 6 \leq X_{1} \leq 9 \\
=\frac{12-X_{1}}{2} ; 9 \leq X_{1} \leq 12
\end{array}\right. \\
& \text { uB aik [12] }\left\{\begin{array}{c}
0: X_{1} \leq 10 \\
=\frac{x_{1}-12}{a}: 10 \leq X_{1} \leq 13 \\
1: X_{1} \geq 13
\end{array}\right. \\
& =0,67
\end{aligned}
$$

penelitian $=2$

$$
\begin{aligned}
& \text { uKurong [2] }\left\{\begin{array}{c}
1: X_{1}=0 \\
\frac{1-X_{1}}{1} ; 0 \leq X_{1} \leq 1 \\
0: X_{1} \geq 1
\end{array}\right. \\
& \text { uCukup [2] }\left\{\begin{array}{c}
0: X_{1} \leq 1 \text { atou } X_{1} \geq 2 \\
=\frac{x_{1}-1}{1}: 1 \leq X_{1} \leq 2 \\
=1 ; X_{1}=2
\end{array}\right. \\
& =1 \\
& \text { uB oik [2] }\left\{\begin{array}{c}
0: X_{1} \leq 2 \\
=\frac{x_{1}-2}{1}: 2 \leq X_{1} \leq 3 \\
1: x_{1}=3
\end{array}\right.
\end{aligned}
$$

pengabdian $=1$

$$
\begin{gathered}
\text { uKurong [1] }\left\{\begin{array}{c}
1: X_{1}=0 \\
=\frac{1-x_{1}}{1} ; 0 \leq X_{1} \leq 1 \\
0: X_{1} \geq 1
\end{array}\right. \\
\text { uCukup [1] }\left\{\begin{array}{c}
0: X_{1} \leq 1 \text { atou } X_{1} \geq 2 \\
=\frac{x_{1}-1}{1}: 1 \leq X_{1} \leq 2 \\
=1: X_{1}=2
\end{array}\right.
\end{gathered}
$$

$$
\text { uB oik [1] }\left\{\begin{array}{c}
0: X_{1} \leq 2 \\
=\frac{x_{1}-2}{1}: 2 \leq X_{1} \leq 3 \\
1: X_{1}=3
\end{array}\right.
$$

Komposisi Aturan

Dari aturan predikat yang ada, dapat dihasilkan komposisi sebagai berikut :

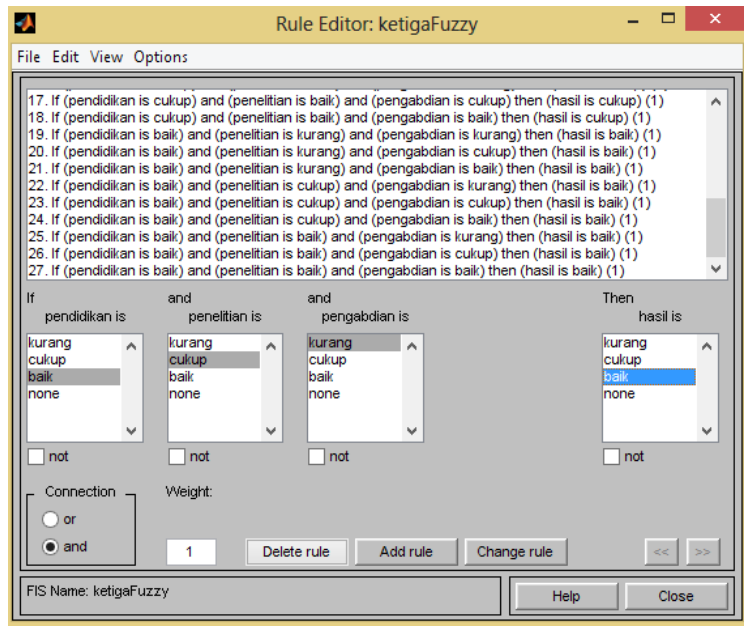

Gambar 6. Komposisi Aturan 
Aturan yang dibentuk 27 rules.

$\underline{\text { Penalaran (Inferensi) }}$

If (pendidikan is baik) and (penelitian is cukup) and (pengabdian is kurang) then (hasil is baik)

$\propto$-hasil $=$ ppendidikanBaik $\cap$ ppenelitianCukup $\cap$ ppengabdianKurang

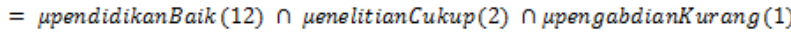

$=\min (0,67 ; 1 ; 0)$

$=0$

$\underline{\text { Defuzifikasi }}$

$$
\begin{aligned}
Z & =\frac{12.0,67+2.1+1.0}{0,67+1+0} \\
& =6,01
\end{aligned}
$$

Dari percobaan tersebut didapat hasil 6,01 yang termasuk hasil baik.

code untuk proses sebagai berikut:

$\mathrm{a}=$ readfis('ketigaFuzzy')

out=evalfis([handles. pendidikan handles. penelitian

handles. pengabdian], a)

\section{IV.KESIMPULAN DAN SARAN}

\section{A. KESIMPULAN}

Kesimpulan setelah dilakukan pengujian pada penelitian ini sebagai berikut:

1. Hasil pengujian 2,36 lebih kecil dari hasil penalaran

2. Diperlukan 27 rules untuk melakukan penerapan logika Fuzzy pada penelitian ini

3. Aplikasi dapat bekerja dengan baik dan dapat digunakan serta dibandingkan dengan metode lain.

\section{B. SARAN}

1. Perlu dilakukan penelitian lanjut dengan melakukan koneksi pada database dan diterapkan pada sistem informasi

2. Breakdown variabel agar lebih khusus dan penilaiannya lebih akurat.

\section{REFERENSI}

[1] Andreas Widiyantoro, T. S. (2014). Menerapkan Logika Fuzzy Mamdani Untuk Menentukan Harga Jual Batik. Techno.COM, Vol. 13, No. 2, Mei 2014: 69-74 (pp. 69-74). Techno.COM

[2] Kusumadewi, S. (2006). Artificial Iinteligence (Teknik dan Aplikasinya). Yogjakarta: Graha Ilmu.

[3] Ross, T. J. (2010). Fuzzy Logic with Engineering Applications, Third Edition. University of New Mexico, USA: John Wiley \& Sons, Ltd. ISBN: 978-0-470-74376-8.

[4] T. Sutojo, M. E. (2011). Kecerdasan Buatan. Yogjakarta: Andi Offset. 